
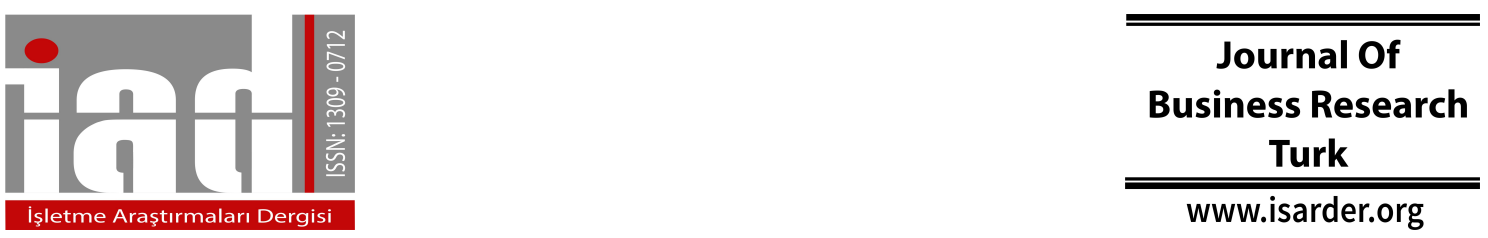

\title{
An Efficiency Evaluation Model for Academic Faculties of a Leading University by Data Envelopment Analysis
}

\author{
Muhammet GÜL \\ Munzur University \\ Faculty of Engineering, \\ Department of Industrial \\ Engineering, 62000 \\ Tunceli, Turkey \\ orcid.org/0000-0002-5319-4289 \\ muhammetgul@munzur.edu.tr
}

\author{
Melih YÜCESAN \\ Munzur University \\ Faculty of Engineering, \\ Department of Mechanical \\ Engineering, 62000 \\ Tunceli, Turkey \\ orcid.org/0000-0001-6148-4959 \\ melihyucesan@munzur.edu.tr
}

\author{
Onur DUMAN \\ Yildiz Technical University \\ Faculty of Mechanical \\ Engineering, Department of \\ Industrial Engineering, \\ 34349, Istanbul, Turkey \\ orcid.org/0000-0003-1784-8609 \\ onurduman3@gmail.com
}

\begin{abstract}
Data envelopment analysis (DEA) is a linear programming based data analytic method for measuring the relative efficiency of organisational units where the presence of multiple inputs and outputs makes comparisons difficult. Academic departments have critical importance for a university so we agree to research and compare about academic faculties in a leading university in Turkey. The aim of the study is to measure the relative efficiency of the academic faculties and determine the efficient/inefficient ones in the studied university. 12 faculties of the university are investigated within the scope of this study. The input variables are considered as total number of academic staff, total number of non-academic staff, number of students and the output variables are as number of publications, number of projects and the percentage of budget used. While results of CCR model show an average of $90.5 \%$ relative efficiency value, five faculties are found $100 \%$ efficient according to the CCR model. According to BCC model, the results have an average of $93.7 \%$ and 6 faculties are $100 \%$ efficient. In terms of the potential improvements evaluated for each inefficient faculty, it is seen that faculty of mechanical engineering and faculty of civil engineering are the ones requiring the most improvement. This paper contributes to the literature a lot however it is a new and proper study on efficiency analysis of faculties of a Turkish university. On conclusion of the DEA efficiency scores, the existence of misallocation of resources or/and inefficient applications to the faculties' academic development are uncovered.
\end{abstract}

Keywords: data envelopment analysis, efficiency, academic faculties

\section{Introduction}

With increasing number of students enrolling in Turkish universities, leading universities has faced with the problem of providing higher education in a more effective manner that enables existing resources to be used to meet increasing demand 
for education. As the most advanced city of Turkey, Istanbul has the most leading public universities. Increasing competition and university management' desire to reach a better place in overall ranking by utilizing scarce resources indicate that efficiency evaluation may become more common among these universities. Each university has a certain number of faculties. The evaluation of the efficiency of these academic faculties is part of the process of resource allocation within a university (Lopes and Lanzer, 2002). Academic faculties compete and cooperate with others within a university to demonstrate their capabilities to the stakeholders inside and outside the university. This prompts university management to use a permanent process of cross-evaluation of departments within the university.

DEA as a data oriented approach is frequently applied by researchers for evaluating the efficiency of a set of decisions making units (DMUs) which convert multiple inputs into multiple outputs. Especially in the recent literature, several studies are carried out in academic environments to measure performance and efficiency using DEA method. Each study is distinguished from its scope, DMUs, and input/output variables. A brief explanation of these related studies is provided in the following. It is noted that these studies can deal with efficiencies of universities, academic sub units within universities and their environments. The focus of this study is related with the faculties as sub units of the universities.

Avkiran (2001) focuses on the evaluation of the relative efficiency of Australian universities using DEA. They propose three performance models as overall performance, performance on delivery of educational services, and performance on feepaying enrolments. They conclude based on 1995 data that the universities perform well on technical and scale efficiency but there is room for improving performance on feepaying enrolments. Lopes and Lanzer (2002) deal with the issue of performance evaluation of fifty-eight academic departments at a Brazilian university using DEA. The results of DEA in the dimensions of teaching, research, service and quality are modelled under fuzzy environment and then a single index of performance for each department is generated. Tauer et al. (2007) study for technical and allocative efficiencies of academic departments in the College of Agriculture and Life Sciences at Cornell University using DEA. They use various specifications of outputs and inputs to determine sensitivity of results to specification. It is concluded that allocations of faculty time between teaching, research, and extension vary by department and are used as unique prices in calculating allocative efficiencies. Kao and Hung (2008) apply DEA to assess the relative efficiency of the academic departments at a university in Taiwan. They consider outputs as total credit-hours, publications, and external grants; and the inputs as personnel, operating expenses, and floor space. Tzeremes and Halkos (2010) apply bootstrapped DEA in order to determine the performance levels of 16 departments of a public owned university in Greece. They conclude that there are strong inefficiencies among the departments, indicating misallocation of resources or/and inefficient application of departments policy developments. Agha et al. (2011) study the evaluation of the relative technical efficiencies of academic departments at the Islamic University in Gaza during the years 2004-2006 using DEA. They use operating expenses, credit hours and training resources as inputs and number of graduates, promotions and public service activities as outputs variables. Results of their study show that the average efficiency score is $68.5 \%$ and that there are 10 efficient departments out of the 30 studied. Al-Shayea and Battal (2013) investigate the efficiency of eighteen faculties in a university in Saudi Arabia for 
the academic year 2011-2012 using DEA. They use the number of students enrolled, the number of teachers and staff as inputs, and the total number of students with a bachelor's degree and a number of research as outputs. The results show that $55.5 \%$ are efficient with average of 0.88 in terms of variable return to scale efficiency. The university obtains average scale efficiency 0.68 and only three faculties reach at the frontier.

The aim of the paper is to estimate and analyse the efficiency of faculties of a leading university for the year 2014 using DEA. Although there are numerous studies focused on the efficiency of universities, university departments and so on in different countries around the world using various parametric and non-parametric methods (Kokkelenberg et al. 2008; Al-Shayea and Battal, 2013; Izadi et al. 2002; Glass et al. 2006; McMillan and Chan, 2006; Worthington and Lee, 2008; Abbott and Doucouliagos, 2003; Tzeremes and Halkos, 2010; Johnes and Johnes, 1993; Tauer et al. 2007; Kao and Hung, 2008; Colbert et al. 2000; Agha et al. 2011), it is limited in Turkey. Therefore, we aim at contributing the current literature by this way considering efficiency analysis of faculties of a Turkish university.

\section{Material and Method}

In this section, we present the data used in evaluating the efficiency of faculties of the observed university and DEA methodology, respectively.

\subsection{Data}

The observed university has 12 faculties. Considering all selection criteria, the research sample includes 12 DMUs spanning all of the faculties as shown in Table 1.

Table 1 Decision making units

\begin{tabular}{cl}
\hline$\#$ & Faculties (DMUs) \\
\hline 1 & Faculty of Education \\
2 & Faculty of Electrical \& Electronics \\
3 & Faculty of Arts \& Science \\
4 & Faculty of Naval Architecture and Maritime \\
5 & Faculty of Economic and Administrative Sciences \\
6 & Faculty of Civil Engineering \\
7 & Faculty of Chemical and Metallurgical Engineering \\
8 & Faculty of Mechanical Engineering \\
9 & Faculty of Architecture \\
10 & Faculty of Art \& Design \\
11 & Technical Vocational School of Higher Education \\
12 & School of Foreign Languages \\
\hline
\end{tabular}

To ensure meaningful efficiency scores, the number of DMUs must be large enough relative to the number of input and output variables. We have 3 inputs and 3 outputs variables as in Table 2. We obtain input data from Academic Activity Report of the observed university for the year 2014. On the other hand, output data is provided by three various source. We provide data of number of publications from encourage publication list for the semester 2013-2014. While the data of number of projects is 
obtained from the university project support office, the percentage of budget used data is received from Directorate of Strategy Development of the university.

After input and output variables were finalized, a data sheet is designed in such a way that the values of these variables are filled in by different departments and units. University website, publications, and brochures are used in data collection. The collected data within the scope of this study are shown in Table 3. All variables are belonged to the year 2014 except from the variable number of publication. NP variable is included by 2013-2014 academic year data (1.10.2013-30.09.2014) because the data after September 2014 has not published yet. It will be published after 2014-2015 academic year. Another reason that we used 2013-2014 academic year's data is that most of data belongs to the year 2014 .

\section{Table 2 Data type and source}

\begin{tabular}{ll}
\hline Variable & Data source \\
\hline $\begin{array}{l}\text { Total Number of Academic Staff (NA) } \\
\text { Total Number of Non-academic Staff (NN) }\end{array}$ & $\begin{array}{l}\text { Academic Activity Report of the year 2014 } \\
\text { Academic Activity Report of the year } 2014\end{array}$ \\
$\begin{array}{l}\text { Number of Students (NS) } \\
\text { Number of Publications (PB): How many SCI, }\end{array}$ & Academic Activity Report of the year 2014 \\
$\begin{array}{l}\text { SSCI or AHCI indexed publications are } \\
\text { produced for 1 year by the faculty? }\end{array}$ & 2013-2014 Encourage Publication List \\
$\begin{array}{l}\text { Number of Projects (NP): How many projects } \\
\text { are produced for 1 year by the faculty? }\end{array}$ & Project Support Office \\
$\begin{array}{l}\text { Percentage of Budget Used (UB): What } \\
\text { percentage is used for budget which is } \\
\text { allocated at the beginning of year? }\end{array}$ & Directorate of Strategy Development of the \\
\hline
\end{tabular}

Table 3 Collected data

\begin{tabular}{lllllll}
\hline \multirow{2}{*}{ Faculty (DMUs) } & Inputs & \multicolumn{5}{c}{ Outputs } \\
\cline { 2 - 7 } & $N S$ & $N A$ & $N N$ & $P B$ & $N P$ & UB (\%) \\
\hline Faculty of Education & 1402 & 111 & 19 & 16 & 6 & 99.1 \\
Faculty of Electrical \& Electronics & 3229 & 170 & 24 & 94 & 12 & 99.59 \\
Faculty of Arts \& Science & 2882 & 320 & 37 & 178 & 47 & 99.21 \\
Faculty of Naval Architecture and Maritime & 1162 & 48 & 16 & 57 & 5 & 98.54 \\
Faculty of Economic and Administrative & 2326 & 112 & 16 & 10 & 2 & 99.34 \\
Sciences & 4073 & 178 & 36 & 147 & 22 & 99.49 \\
Faculty of Civil Engineering & 2285 & 164 & 33 & 237 & 39 & 99.64 \\
Faculty of Chemical and Metallurgical & 4310 & 156 & 30 & 123 & 16 & 99.4 \\
Engineering & 1494 & 130 & 19 & 5 & 3 & 99.15 \\
Faculty of Mechanical Engineering & 532 & 69 & 19 & 1 & 2 & 99.16 \\
Faculty of Architecture & 2321 & 49 & 19 & 0 & 1 & 99.81 \\
Faculty of Art \& Design & & & & & & \\
Technical Vocational School of Higher & 3878 & 162 & 12 & 0 & 0 & 99.62 \\
Education & & & & & \\
School of Foreign Languages & &
\end{tabular}

Table 3 shows the average of the collected variables. PB variable of Technical Vocational School of Higher Education and School of Foreign Languages equal zero 
which means that they have not published any publication through 2013-2014 academic year. NP of School of National Palaces \& Historical Buildings and School of Foreign Languages equal zero which means that they have not produced any projects in 2014.

\subsection{DEA methodology}

DEA is a powerful non-parametric method in efficiency evaluation. It is widely used in various sectors recently (Alper et al. 2015; LaPlante and Paradi 2015; Misiunas et al. 2015; Zografidou et al. 2015) as well as academia. DEA gives an efficiency score by dealing with multiple inputs and multiple outputs. The relative efficiency of a DMU is calculated relative to all other DMUs (McMillan and Chan, 2006). In our case study, 12 faculties of a leading Turkish university specify the DMUs. The traditional DEA approach is proposed by Charnes et al. (1978). It is known as CCR model and calculates pure technical efficiency and scale efficiency scores. Then another version of DEA is developed by Banker et al. (1984). It is known as BCC model and calculates only pure technical efficiency scores. The main difference between BCC and CCR models is the treatment of returns to scale. The CCR model is based on the evaluation of constant returns to scale (CRS). The BCC model is on variable returns to scale (VRS) (Abbott and Doucouliagos, 2003; Colbert et al. 2000). For each model, fractional programminglinear programming transformation is used considering input-oriented and outputoriented forms. Input-oriented DEA models express the reductions it would be required to make in the inputs of the assessed DMU so that it can be become qualified as efficient. Similarly, output-oriented DEA models identify the necessary increase in output to achieve the same effect.

The input-oriented CCR model is presented by fractional programming mathematically, as follows (Colbert et al. 2000; Abbott and Doucouliagos, 2003; McMillan and Chan, 2006):

$$
\begin{aligned}
& \max \theta_{m}=\frac{\sum_{i=1}^{t} v_{i} y_{i m}}{\sum_{j=1}^{s} u_{j} x_{j m}} \\
& \text { s.t. } \\
& \quad \frac{\sum_{i=1}^{t} v_{i} y_{i k}}{\sum_{j=1}^{s} u_{j} x_{j k}} \leq 1, \mathrm{k}=1, \ldots \ldots, \mathrm{n} \\
& u_{j}, v_{i} \geq 0, \forall \mathrm{j}, \mathrm{i}
\end{aligned}
$$

where, $y_{i k}, x_{j k}$ are the amount of inputs and outputs of the DMU $k$; and $v_{i}, u_{j} \geq 0$ are the weight given to outputs and inputs. $m$ is referred to the DMU that is measured among $k=1, \ldots, n$ DMUs. Instead of fractional form, it is generally used based on linear programming form as follows: 
$\max \theta_{m}=\sum_{i=1}^{t} v_{i} y_{i m}$

s.t.

$$
\begin{aligned}
& \sum_{j=1}^{s} u_{j} x_{j m}=1 \\
& \sum_{i=1}^{t} v_{i} y_{i k}-\sum_{j=1}^{s} u_{j} x_{j k} \geq 0 \\
& u_{j}, v_{i} \geq 0, \forall \mathrm{j}, \mathrm{i}
\end{aligned}
$$

The BCC model considering input-oriented form can be summarized as in the following (Sarica and Or, 2007):

$$
\begin{aligned}
\max & \theta_{m}=\sum_{i=1}^{t} v_{i} y_{i m}-v_{m} \\
\text { s.t. } & \\
& \sum_{j=1}^{s} u_{j} x_{j m}=1 \\
& \sum_{i=1}^{t} v_{i} y_{i k}-\sum_{j=1}^{s} u_{j} x_{j k}-v_{m} \leq 0 \\
& u_{j}, v_{i} \geq 0, \forall \mathrm{j}, \mathrm{i}
\end{aligned}
$$

\section{Application of the efficiency evaluation model for a leading university}

We divide this section into three subsections as establishment of the model, determining the efficiency evaluation of the faculties and determination of target values, respectively.

\subsection{Establishment of the model}

In this study, we deal with the efficiency evaluation of the faculties of the observed university using DEA methodology. DEA Solver is used to measure the technical efficiency of the faculties based on both CCR and BCC input oriented models. As mentioned earlier, most of previous studies only used BCC model. In this study, both CCR and BCC input oriented models are used to select the model that fairly represents the behaviour of the system. Due to the fact that in a university environment, it is easier to control the inputs rather than the outputs, the DEA input oriented model is preferred to compute the efficiency of these faculties.

\subsection{Efficiency evaluation of the faculties}

Table 4 shows the efficiency, the reference set(s) (benchmarks) for each DMU. Faculties of Arts \& Science, Naval Architecture and Maritime, Chemical and Metallurgical Engineering, Art \& Design and School of Foreign Languages are efficient. Faculty of Education has $87 \%$ efficiency, Faculty of Electrical \& Electronics has $81 \%$ efficiency and Faculty of Architecture has $84 \%$ efficiency. These three faculties have not bad scores and will be efficient with a few improvements. Technical Vocational School of Higher Education has top score with $99 \%$ in inefficient faculties. Faculty of Economic and Administrative Sciences has second top score with $91 \%$ efficiency. Faculty of Civil Engineering has least score with $68 \%$ so it is needed to make some improvements to be more efficient. Finally, Faculty of Mechanical Engineering has $74 \%$ efficiency. It is the second least score among all faculties. 
M. Gül - M. Yücesan - O Duman 9/3 (2017) 60-71

Table 4 Input-oriented CRS efficiency

\begin{tabular}{llll}
\hline DMUs & DMU Name & $\begin{array}{l}\text { Input-oriented } \\
\text { CRS scores }\end{array}$ & $\begin{array}{l}\text { Reference } \\
\text { set(s) }\end{array}$ \\
\hline 1 & Faculty of Education & 0.87 & $4,7,12$ \\
2 & Faculty of Electrical \& Electronics & 0.81 & $4,7,12$ \\
3 & Faculty of Arts \& Science & 1.00 & 3 \\
4 & Faculty of Naval Architecture and Maritime & 1.00 & 4 \\
5 & Faculty of Economic and Administrative Sciences & 0.91 & 4,12 \\
6 & Faculty of Civil Engineering & 0.68 & $4,7,12$ \\
7 & Faculty of Chemical and Metallurgical Engineering & 1.00 & 7 \\
8 & Faculty of Mechanical Engineering & 0.74 & 4,7 \\
9 & Faculty of Architecture & 0.84 & 4,12 \\
10 & Faculty of Art \& Design & 1.00 & 10 \\
11 & Technical Vocational School of Higher Education & 0.99 & 4 \\
12 & School of Foreign Languages & 1.00 & 12 \\
\hline
\end{tabular}

Note in Table 5 that all inefficient DMUs have (reference sets) benchmarks. These DMUs are asked to learn how to transform their inputs to outputs. In other words, inefficient departments should adopt their benchmarks' policies and techniques in the production process. For example, as shown in Table 4, the reference sets of Mechanical Engineering are Faculty of Naval Architecture and Maritime and Faculty of Chemical and Metallurgical Engineering. Therefore, for Mechanical Engineering to become efficient, it can learn best practices from these faculties. Further, it is observed that DMU 4 (Faculty of Naval Architecture and Maritime) is the most recurring benchmark. It was referenced for 8 times, which means that there are 8 faculties which could learn from DMU 4 best practices and thus become efficient. The same can be said about the other recurring benchmark like DMU 12 which is referenced for 6 times. In other words, at least 6 inefficient faculties can improve their efficiencies by learning from the methods and techniques adopted by these DMUs. In summary, the scores of DMUs range from $68 \%$ to $100 \%$. 5 DMUs are efficient and 7 are inefficient. Faculty of Civil Engineering has the least efficiency score of $68 \%$.

In order to have more insights into the applicable model, BCC efficiency scores are calculated and shown in Table 5. It is noted that BCC yields more efficient departments than CCR. These results are expected due to two reasons. First, theoretically $\mathrm{CCR}$ and $\mathrm{BCC}$ are ratios that share the same denominator while the numerator of $\mathrm{BCC}$ ratio is greater than the numerator in CCR ratio. Secondly, BCC relaxes the slack variables to be greater than zero and adding lambda constraint. Table 5 shows that the scores of efficiencies which are higher than in CCR model. Faculties are more efficient and Technical Vocational School of Higher Education which is inefficient in CCR model is efficient in BCC model. 
Table 5 Input-oriented VRS efficiency

\begin{tabular}{llll}
\hline \multirow{2}{*}{ DMUs } & DMU Name & $\begin{array}{l}\text { Input-oriented } \\
\text { CRS scores }\end{array}$ & $\begin{array}{l}\text { Reference } \\
\text { set(s) }\end{array}$ \\
\hline 1 & Faculty of Education & 0.97 & $4,7,10,12$ \\
2 & Faculty of Electrical \& Electronics & 0.88 & $7,10,11,12$ \\
3 & Faculty of Arts \& Science & 1.00 & 3 \\
4 & Faculty of Naval Architecture and Maritime & 1.00 & 4 \\
5 & Faculty of Economic and Administrative Sciences & 0.97 & $4,7,10,11,12$ \\
6 & Faculty of Civil Engineering & 0.71 & $4,7,11,12$ \\
7 & Faculty of Chemical and Metallurgical Engineering & 1.00 & 7 \\
8 & Faculty of Mechanical Engineering & 0.78 & $4,7,11,12$ \\
9 & Faculty of Architecture & 0.91 & $4,7,10,12$ \\
10 & Faculty of Art \& Design & 1.00 & 10 \\
11 & Technical Vocational School of Higher Education & 1.00 & 11 \\
12 & School of Foreign Languages & 1.00 & 12 \\
\hline
\end{tabular}

\subsection{Determination of target values}

Table 6 shows that for inefficient departments, the amounts by which these DMUs should decrease their inputs to become efficient are calculated using the CCR model. It is noticed that Faculty of Electrical \& Electronics, Faculty of Civil Engineering, Faculty of Mechanical Engineering and Technical Vocational School of Higher Education should decrease their number of students by certain amounts to reach the targeted level shown in order to be efficient. Faculty of Education, Faculty of Economic and Administrative Sciences, Faculty of Architecture should also decrease their number of students by little amounts. Faculty of Education, Faculty of Electrical \& Electronics, Faculty of Economic and Administrative Sciences, Faculty of Civil Engineering, Faculty of Mechanical Engineering and Faculty of Architecture should also decrease their academic staff by certain amounts. Same faculties in addition to Technical Vocational School of Higher Education should decrease number of their non-academic staff.

Table 6 CCR model input target

\begin{tabular}{lllll}
\hline \multirow{2}{*}{ DMUs } & \multicolumn{3}{c}{ DMU Name } & \multicolumn{3}{c}{ Efficient Input Target } \\
\cline { 2 - 4 } 2 & Faculty of Education & 1221.94 & 52.56 & 16.55 \\
2 & Faculty of Electrical \& Electronics & 1430.72 & 73.47 & 19.59 \\
3 & Faculty of Arts \& Science & 2882.00 & 320.00 & 37.00 \\
4 & Faculty of Naval Architecture and Maritime & 1162.00 & 48.00 & 16.00 \\
5 & Faculty of Economic and Administrative Sciences & 2129.71 & 88.61 & 14.64 \\
6 & Faculty of Civil Engineering & 1739.07 & 106.65 & 24.54 \\
7 & Faculty of Chemical and Metallurgical Engineering & 2285.00 & 164.00 & 33.00 \\
8 & Faculty of Mechanical Engineering & 1577.51 & 90.58 & 22.28 \\
9 & Faculty of Architecture & 1255.42 & 51.91 & 15.96 \\
10 & Faculty of Art \& Design & 532.00 & 69.00 & 19.00 \\
11 & Technical Vocational School of Higher Education & 1176.97 & 48.61 & 16.20 \\
12 & School of Foreign Languages & 3878.00 & 162.00 & 12.00 \\
\hline
\end{tabular}


Table 7 shows that for inefficient departments, the amounts by which these DMUs should increase their outputs to become efficient are calculated using the CCR model. Faculty of Education, Faculty of Economic and Administrative Sciences, Faculty of Architecture and Technical Vocational School of Higher Education should increase their publications to be efficient. There is only Technical Vocational School of Higher Education which is needed to increase their number of projects by certain amounts. Target and current number of projects are almost same for other faculties and target percentage of using budget is completely same with current variables.

Table 7 CCR model output target

\begin{tabular}{lllll}
\hline \multirow{2}{*}{ DMUs $\quad$ DMU Name } & \multicolumn{3}{l}{ Efficient Output Target } \\
\cline { 2 - 5 } & PB & NP & UB \\
\hline 1 & Faculty of Education & 62.22 & 6.00 & 99.10 \\
2 & Faculty of Electrical \& Electronics & 94.00 & 12.00 & 99.59 \\
3 & Faculty of Arts \& Science & 178.00 & 47.00 & 99.21 \\
4 & Faculty of Naval Architecture and Maritime & 57.00 & 5.00 & 98.54 \\
5 & Faculty of Economic and Administrative Sciences & 37.03 & 3.24 & 99.34 \\
6 & Faculty of Civil Engineering & 147.00 & 22.00 & 99.49 \\
7 & Faculty of Chemical and Metallurgical Engineering & 237.00 & 39.00 & 99.64 \\
8 & Faculty of Mechanical Engineering & 123.00 & 17.43 & 99.40 \\
9 & Faculty of Architecture & 55.51 & 4.86 & 99.15 \\
10 & Faculty of Art \& Design & 1.00 & 2.00 & 99.16 \\
11 & Technical Vocational School of Higher Education & 57.73 & 5.06 & 99.81 \\
12 & School of Foreign Languages & 0.00 & 0.00 & 99.62 \\
\hline
\end{tabular}

Table 8 shows that input targets of faculties according to BCC model. The values of CCR and BCC efficiencies are close to each other. According to BCC model, Faculty of Civil Engineering and Faculty of Mechanical Engineering need to be decreased their student's number by certain amounts. DMU 1, 2, 6, 8 and 9 need to be decreased their academic staff's number and DMU 2, 6, 8, 9 need to be decreased their non-academic staff's number.

Table 8 BCC model input target

\begin{tabular}{lllll}
\hline \multirow{2}{*}{ DMUs } & \multicolumn{1}{c}{ DMU Name } & \multicolumn{3}{c}{ Efficient Input Target } \\
\cline { 3 - 5 } & NS & NA & NN \\
\hline 1 & Faculty of Education & 1361.36 & 85.67 & 18.44 \\
2 & Faculty of Electrical \& Electronics & 2861.26 & 149.47 & 21.26 \\
4 & Faculty of Arts \& Science & 2882.00 & 320.00 & 37.00 \\
5 & Faculty of Naval Architecture and Maritime & 1162.00 & 48.00 & 16.00 \\
6 & Faculty of Economic and Administrative Sciences & 2275.08 & 109.54 & 15.64 \\
7 & Faculty of Civil Engineering & 2287.14 & 128.13 & 25.91 \\
8 & Faculty of Chemical and Metallurgical Engineering & 2285.00 & 164.00 & 33.00 \\
9 & Faculty of Mechanical Engineering & 2313.03 & 122.29 & 23.51 \\
10 & Faculty of Architecture & 1364.69 & 86.12 & 17.35 \\
11 & Technical Vocational School of Higher Education & 532.00 & 69.00 & 19.00 \\
12 & School of Foreign Languages & 2321.00 & 49.00 & 19.00 \\
\hline
\end{tabular}


According to Table 9, Faculty of Education and Faculty of Architecture should increase their publications to be efficient. Faculty of Electrical \& Electronics and Faculty of Mechanical Engineering need to be increased their number of projects by certain amounts. Percentage of using budget is same for all faculties.

Table 9 BCC model output target

\begin{tabular}{lllll}
\hline \multirow{2}{*}{ DMUs } & \multicolumn{3}{c}{ DMU Name } & \multicolumn{3}{c}{ Efficient Output Target } \\
\cline { 3 - 5 } & PB & NP & UB \\
\hline 1 & Faculty of Education & 38.48 & 6.00 & 99.10 \\
2 & Faculty of Electrical \& Electronics & 94.00 & 15.68 & 99.59 \\
3 & Faculty of Arts \& Science & 178.00 & 47.00 & 99.21 \\
4 & Faculty of Naval Architecture and Maritime & 57.00 & 5.00 & 98.54 \\
5 & Faculty of Economic and Administrative Sciences & 11.21 & 2.000 & 99.34 \\
6 & Faculty of Civil Engineering & 147.00 & 23.657 & 99.49 \\
7 & Faculty of Chemical and Metallurgical Engineering & 237.00 & 39.00 & 99.64 \\
8 & Faculty of Mechanical Engineering & 123.00 & 19.335 & 99.40 \\
9 & Faculty of Architecture & 16.53 & 3.00 & 99.15 \\
10 & Faculty of Art \& Design & 1.00 & 2.00 & 99.16 \\
11 & Technical Vocational School of Higher Education & 0.00 & 1.00 & 99.81 \\
12 & School of Foreign Languages & 0.00 & 0.00 & 99.62 \\
\hline
\end{tabular}

\section{Conclusion}

This study applies input oriented DEA approach to measure the technical efficiency of faculties of a leading university in Turkey. The DMUs of the study are 12 faculties and the time period covers the year 2014. Three input variables and three output variables are selected to represent efficiencies of the faculties. Number of students, number of academic and non-academic staff are used as inputs, while the outputs include number of projects, number of publications and percentage of budget used.

The results of CCR model have an average of $90.5 \%$. Five faculties are $100 \%$ efficient according to the CCR model. According to BCC model, the results have an average of $93.7 \%$ and 6 faculties are $100 \%$ efficient. The potential improvements are then evaluated for each inefficient faculty. It is found that Faculty of Mechanical Engineering and Faculty of Civil Engineering are the faculties which are required the most improvements. Finally, the target values are calculated for each faculty in order to help decision makers in the inefficient departments select the most promising variables to improve their efficiencies. Based on this, it is recommended that university administration encourage and motivate its academic staff to focus more on publications which is mainly the criteria of promotion. Another important point is that student's number and academic staff's number should be decreased.

There are limited studies in Turkey about comparing academic faculties or universities based on DEA so this study aims to contribute to the literature with this way and provides university administration a model that is extremely useful to evaluate relative efficiency. If there have been more faculties to evaluate, this study could give more truthful results. In this study, the percentage of used budget for all DMUs are almost same so it could not effect. The data about the amount of given budget and the 
amount of spent budget by university administration can be added as an extension of this study. Although DEA is such a powerful tool, it should be noted here that this study is deterministic in nature. In other words, it does not deal with outliers. Therefore, it is recommended that other versions of DEA can be used in future studies.

\section{References}

Arenas-Parra, M., Bilbao-Terol, A., \& Jiménez, M. (2016). Standard goal programming with fuzzy hierarchies: a sequential approach. Soft Computing, 20(6), 2341-2352.

Abbott, M., \& Doucouliagos, C. (2003). The efficiency of Australian universities: a data envelopment analysis. Economics of Education review, 22(1), 89-97.

Agha, S. R., Kuhail, I., Nabi, N. A., Salem, M., \& Ghanim, A. (2011). Assessment of academic departments efficiency using data envelopment analysis. Journal of Industrial Engineering and Management, 4(2), 301-325.

Alper, D., Sinuany-Stern, Z., \& Shinar, D. (2015). Evaluating the efficiency of local municipalities in providing traffic safety using the Data Envelopment Analysis. Accident Analysis \& Prevention, 78, 39-50.

Al-Shayea, A. S., \& Battal, A. H. (2013). Evaluating the efficiency of faculties in Qassim University using data envelopment analysis. Journal of Business Administration and Education, 4(2), 132-138.

Avkiran, N. K. (2001). Investigating technical and scale efficiencies of Australian universities through data envelopment analysis. Socio-Economic Planning Sciences, 35(1), 57-80.

Banker, R. D., Charnes, A., \& Cooper, W. W. (1984). Some models for estimating technical and scale inefficiencies in data envelopment analysis. Management science, 30(9), 1078-1092.

Charnes, A., Cooper, W. W., \& Rhodes, E. (1978). Measuring the efficiency of decision making units. European journal of operational research, 2(6), 429-444.

Colbert, A., Levary, R. R., \& Shaner, M. C. (2000). Determining the relative efficiency of MBA programs using DEA. European journal of operational research, 125(3), 656-669.

Glass, J. C., McCallion, G., McKillop, D. G., Rasaratnam, S., \& Stringer, K. S. (2006). Implications of variant efficiency measures for policy evaluations in UK higher education. Socio-economic planning sciences, 40(2), 119-142.

Izadi, H., Johnes, G., Oskrochi, R., \& Crouchley, R. (2002). Stochastic frontier estimation of a CES cost function: the case of higher education in Britain. Economics of education review, 21(1), 63-71.

Johnes, G., \& Johnes, J. (1993). Measuring the research performance of UK economics departments: an application of data envelopment analysis. Oxford economic papers, 332-347.

Kao, C., \& Hung, H. T. (2008). Efficiency analysis of university departments: An empirical study. Omega, 36(4), 653-664. 
Kokkelenberg, E. C., Sinha, E., Porter, J. D., \& Blose, G. L. (2008). The efficiency of private universities as measured by graduation rates, Cornell Higher Education Research Institute Working Paper No. 113 (Ithaca NY, July 2008)

LaPlante, A. E., \& Paradi, J. C. (2015). Evaluation of bank branch growth potential using data envelopment analysis. Omega, 52, 33-41.

Lopes, A. L. M., \& Lanzer, E. A. (2002). Data envelopment analysis-DEA and fuzzy sets to assess the performance of academic departments: a case study at Federal University of Santa Catarina-UFSC. Pesquisa Operacional, 22(2), 217-230.

McMillan, M. L., \& Chan, W. H. (2006). University efficiency: A Comparison and consolidation of results from stochastic and non-stochastic methods. Education economics, 14(1), 1-30.

Misiunas, N., Oztekin, A., Chen, Y., \& Chandra, K. (2015). DEANN: A Healthcare Analytic Methodology of Data Envelopment Analysis and Artificial Neural Networks for the Prediction of Organ Recipient Functional Status. Omega. doi:10.1016/j.omega.2015.03.010

Sarıca, K., \& Or, I. (2007). Efficiency assessment of Turkish power plants using data envelopment analysis. Energy, 32(8), 1484-1499.

Tauer, L. W., Fried, H. O., \& Fry, W. E. (2007). Measuring efficiencies of academic departments within a college. Education economics, 15(4), 473-489.

Tzeremes, N., \& Halkos, G. (2010). A DEA approach for measuring university departments' efficiency. Working paper.

http://mpra.ub.uni-muenchen.de/24029/1/MPRA_paper_24029.pdf [Access July 22, 2015].

Worthington, A. C., \& Lee, B. L. (2008). Efficiency, technology and productivity change in Australian universities, 1998-2003. Economics of education review, 27(3), 285-298.

Zografidou, E., Petridis, K., Arabatzis, G., \& Dey, P. K. (2015). Optimal design of the renewable energy map of Greece using weighted goal-programming and data envelopment analysis. Computers \& Operations Research. doi: 10.1016/j.cor.2015.03.012 